\title{
Radiological investigation of the small intestine
}

\author{
W. G. SCOTT-HARDEN, H. A. R. HAMILTON, AND S. McCALL SMITH \\ From the Cumberland Infirmary, Carlisle
}

SYNOPSIS This paper reports experience with a selective technique of small intestine enemas.

In the past, radiological investigation of the small intestine has relied almost exclusively upon the barium follow-through series. Many variations have been devised to ensure a complete and even filling but none has advanced the accuracy of radiological diagnosis. This technique has failed too often to warrant complacency and an analysis of the causes of failure may help to encourage the adoption of an alternative method of examination.

Certain disadvantages are obvious. The filling of the small intestine is controlled by the rate of delivery through the pylorus and this is unpredictable within each interval of the serial examination. It tends to produce irregular filling and any irritability of the bowel itself further complicates the picture by producing fragmentation and flocculation of the barium column. The opaque coils, by overlapping, may obscure a small lesion. Each film of the series is only a demonstration of the appearances in a moment of time and the pathological segment may never be seen.

These factors militate against a complete survey of the tract but we consider the real limitation of this form of examination to be due to inability to test elasticity of the bowel wall. The barium column in the follow-through series is propelled forward by peristaltic activity and at the same time the maximum diameter of the lumen is controlled by the tone prevailing at the moment. Even following partial gastrectomy, where pyloric control is removed, the intestinal passage of barium is still under the influence of peristaltic activity and the tone remains dominant. Obviously an early lesion, causing minimal constriction, will not be visible if the constriction has not yet reduced the lumen below that permitted by the tone prevailing. A constrictive lesion developing very slowly causes hypertrophy of the proximal bowel wall and this overcomes the tendency to dilate against the obstruction.

Badenoch (1960) stressed the importance of careful radiological examination in every patient suffering from steatorrhoea in the search for intrinsic pathology of the small bowel. He stated, however, that some structural lesions are extremely difficult to demonstrate. Blind loops may be overlooked and fistulae are often difficult to find; diverticula also are frequently unrecognized. Even if some diverticula do fill it is rare to have a complete picture of the total extent of a generalized diverticulosis by means of the follow-through series. We think that this failure to demonstrate diverticula and fistulae is due also to the maintenance of tone and peristaltic activity which prevents the entry of barium into them during the passage of the bolus.

The definition of adhesions may also cause difficulty. Here the diagnosis depends upon the ability to test mobility in each segment of the small bowel in progression, with the patient in varying degrees of posture from the horizontal to the vertical, in order to demonstrate the persistence of an acute kink under conditions of rapid intestinal flow.

Finally, problems of radiological diagnosis arise in the proximal colon when filling by the retrograde colon enema is found to be impossible. In these cases a true definition of the extent and the appearances of the pathological segment is not obtained.

If this is a correct interpretation of the limitations of the ingested opaque meal, relying on peristalsis for progression, the success must depend upon a technique which will be independent of peristaltic activity and prevailing tone. At the same time, the disadvantage of obscuring bowel segments by overlapping must be avoided and, if possible, a double contrast technique must be sought to give a clear picture of the mucosal pattern.

Schatzki (1943) devised an alternative technique which he called the small bowel enema. It was designed to overcome the disadvantage of pyloric control by the introduction of a continuous flow of opaque medium beyond the pylorus, but this method did not gain favour on two counts: 1 The difficulty of attaining duodenal intubation, which occupied trained staff for a protracted period 
without adequate certainty of success; and 2 the disadvantage already mentioned in relation to the follow-through series, namely opacification of the whole small bowel. Greenspon and Lentino (1960) have devised a method of retrograde enterography using a modified Miller-Abbott tube, but this requires the passage of the tube far down the small bowel which adds to the complexity of the procedure.

We report here a variety of lesions of the small bowel demonstrated since the introduction of a simple small bowel enema technique as a standard procedure in this department six years ago. The report includes cases of inflammatory disease, diverticulosis and adhesions of the small bowel, and a case of carcinoma of the ascending colon. No case of tumour of the small bowel has been referred for examination within the period of this series.

The technique of duodenal intubation and the method of achieving a double-contrast small bowel enema are described in detail elsewhere (ScottHarden, 1960). We have limited the quantity of opaque medium to the equivalent of $20 \mathrm{ml}$. of Microtrast diluted to $80 \mathrm{ml}$. with tap water. This amount is only increased when the review of a questionable segment is necessary. A greater quantity tends to cause errors of interpretation by overlay of the opaque coils. Onward progress of the opaque column is achieved by the subsequent injection of tap water and the barium left behind adhering to the mucosa serves to give double contrast.

Modifications of the design of the tube and the enema technique have been reported by Pygott, Street, Shellshear, and Rhodes (1960). One can hope that experiment will evolve further improvements. It is our practice to undertake this procedure, requiring no more than 45 minutes, in the out-patient department and experience has shown no disadvantage.

\section{CASE REPORTS}

CASE 1 R.K., a man aged 45 years, referred by Dr. T. McL. Galloway, was first seen early in 1955 complaining of vague dyspepsia. A barium meal and follow-through at that time failed to demonstrate any ulceration in the stomach or duodenum or demonstrable abnormality of the small intestine. Persistent symptoms and the onset of intestinal haemorrhage called for review in October of the same year, when a small bowel enema showed a narrow segment of jejunum with localized ulceration (Fig. 1). Operation by Mr. J. E. Monro confirmed the lesion which was resected and continuity re-established by end-to-end anastomosis. No other lesion of the small intestine was found at this operation and the specimen was reported by Dr. J. S. Faulds to be of Crohn's disease.

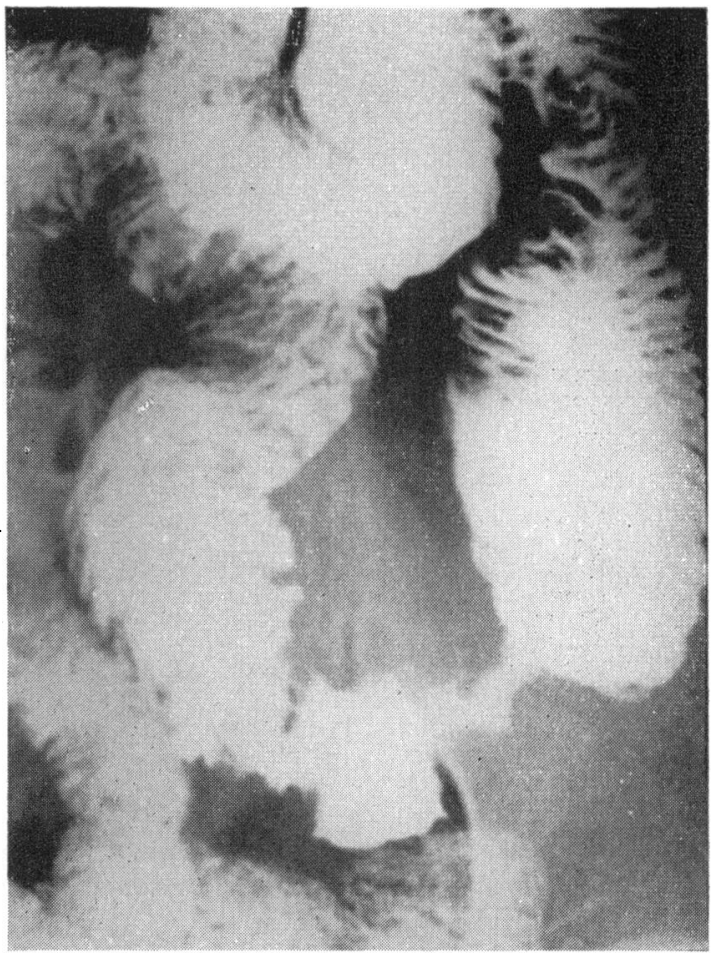

FIG. 1. Case 1: Small bowel enema showing rigid narrowed segment of jejunum contrasted by complete filling of the bowel on each side of the constriction. Crohn's disease.

CASE 2 T.H., a man aged 42, was referred by Dr. Hugh Morton in 1956. This case serves to contrast the appearances of a pathological segment of jejunum in the follow-through series and the double-contrast small bowel enema. In the follow-through series a long segment of jejunum appears as a rigid tube with a cobblestone mucosal pattern (Fig. 2). The small bowel enema, however, shows that this segment retains some degree of elasticity and the cobblestone pattern of the mucosa is ironed out as the dilatation occurs, only to return with the natural contraction when the injection is discontinued (Figs. 3a and $3 b$ ). This suggested that the cobblestone pattern was due to the inability of the mucosal lining to crumple up on account of submucosal oedema or infiltration and was interpreted as non-sclerosing enteritis. No surgical interference was considered and the patient continues at work to the present time.

CASE 3 R.E., a woman aged 49, was referred by Mr. R. M. Hill in 1959. Nine years previously a hemicolectomy had been performed for Crohn's disease. She remained well until March 1959 when she complained of pain in the right iliac fossa and was found to have a tender mass in that area. The retrograde colon enema 


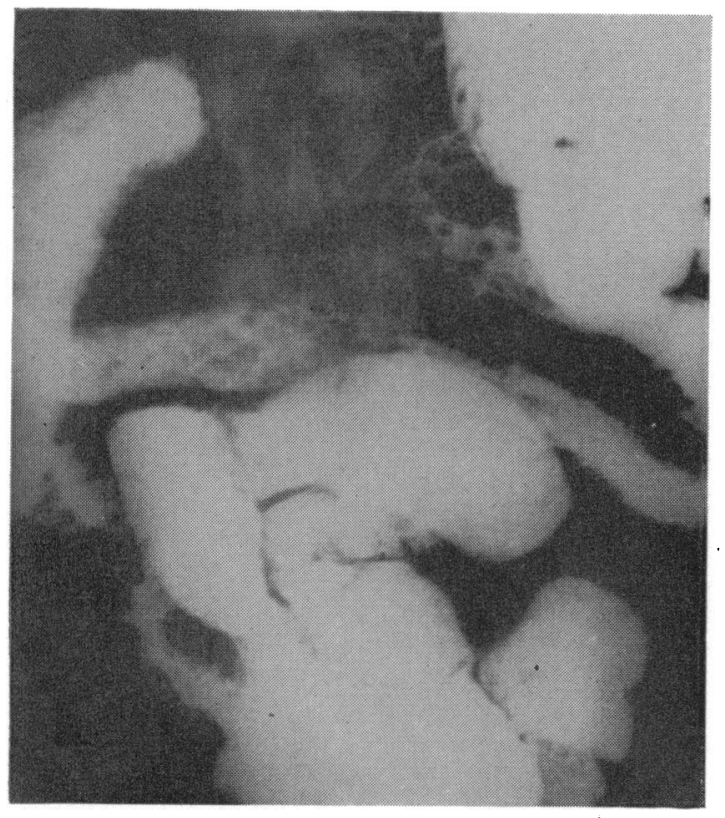

FIG. 2. Case 2: Barium meal and follow-through showing segment of jejunum with cobblestone mucosa and appearing rigid. Non-sclerosing enteritis.

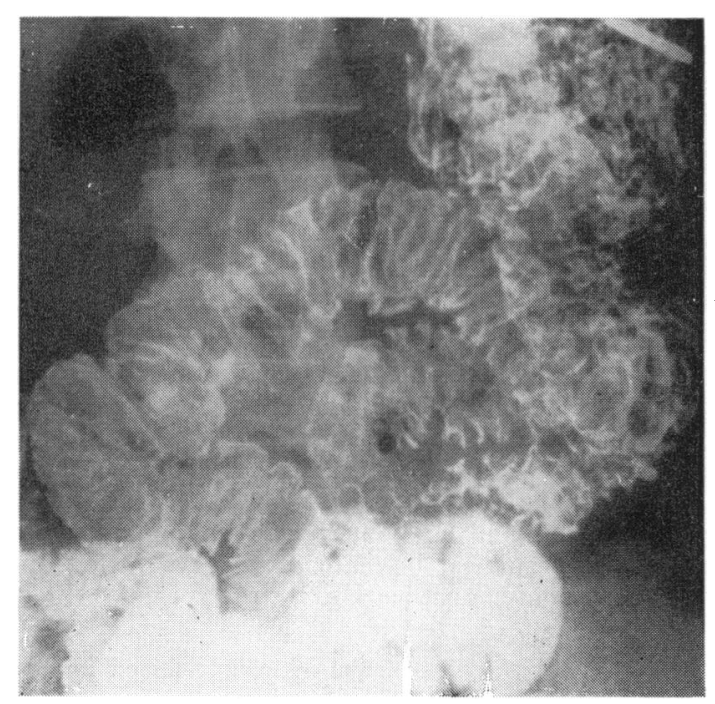

FIG. 3a. Case 2: Small bowel enema with double contrast showing some elasticity and the mucosa no longer cobblestoned. became totally obstructed in the proximal transverse area and no further information was forthcoming. A small bowel enema showed a rigid diseased segment of ileum and an extraluminal track running into the area of the mass. Also a loop of proximal ileum was seen adhering to the mass (Figs. $4 \mathrm{a}$ and $4 \mathrm{~b}$ ). Mr. Hill resected the diseased ileum and colon and the patient's subsequent progress has been satisfactory without suspicion of recurrence so far. The specimen was reported to be of Crohn's disease.

CASE 4 A.M., a woman aged 62 years, was referred by Mr. J. E. Monro in 1960 for investigation of suspected subacute intestinal obstruction. The colon enema failed to penetrate beyond the proximal transverse segment and did not define the nature of the lesion. A small bowel enema six days later showed conclusive evidence of a carcinoma of the ascending colon producing the typical bracket deformity (Fig. 5). This lesion was found to be inoperable and a short circuit only was possible.

CASE 5 T.H., a man aged 41 years, was referred by Mr. A. B. MacLean with a history of episodic upper abdominal pain for five years with occasional vomiting. The bowels were generally regular and the stools normal in consistence and colour except for occasional bursts of diarrhoea. The clinical examination was essentially negative.

The barium meal and follow-through showed no evidence of peptic ulceration in the stomach or duodenum but demonstrated five or six diverticula scattered in the jejunum. A small bowel enema showed very numerous diverticula throughout the whole length of the small

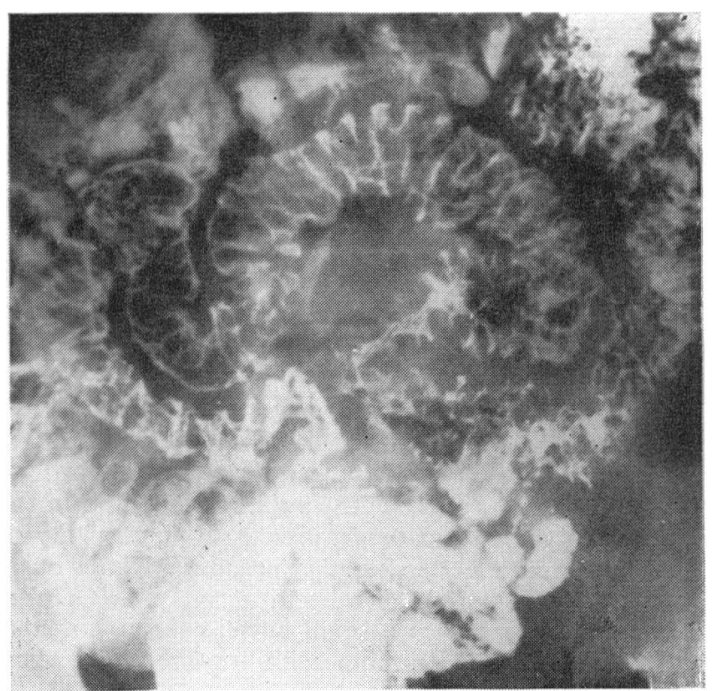

FIG. 3b. Case 2: Same segment of jejunum as in Fig. 3a, showing return of cobblestone pattern as contraction takes place when injection is discontinued. 


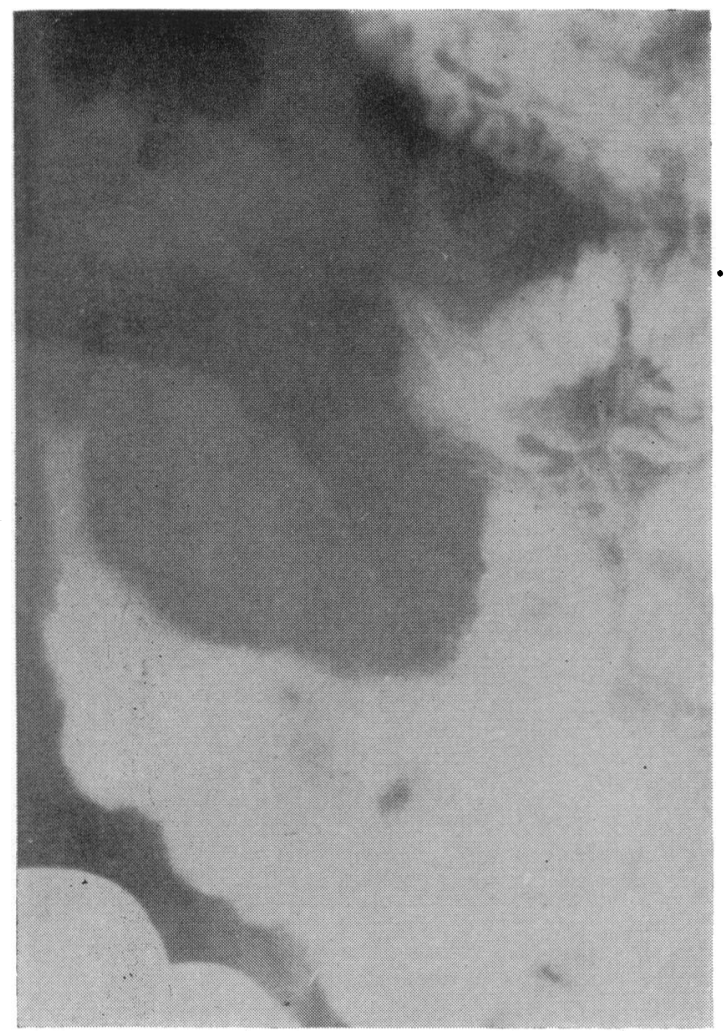

FIG. $4 a$

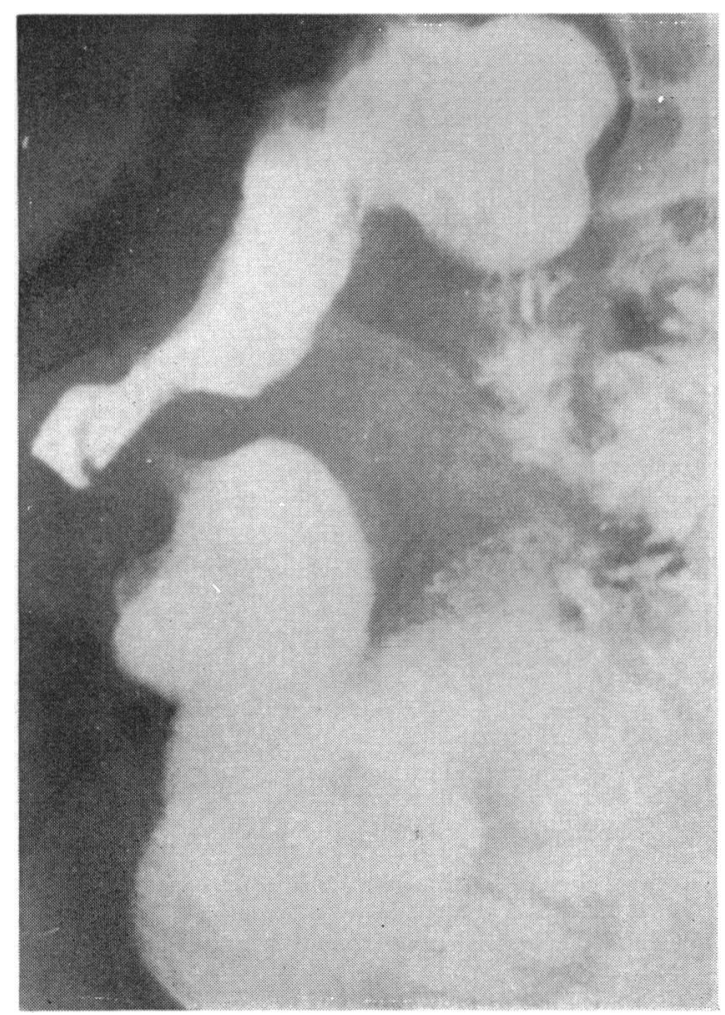

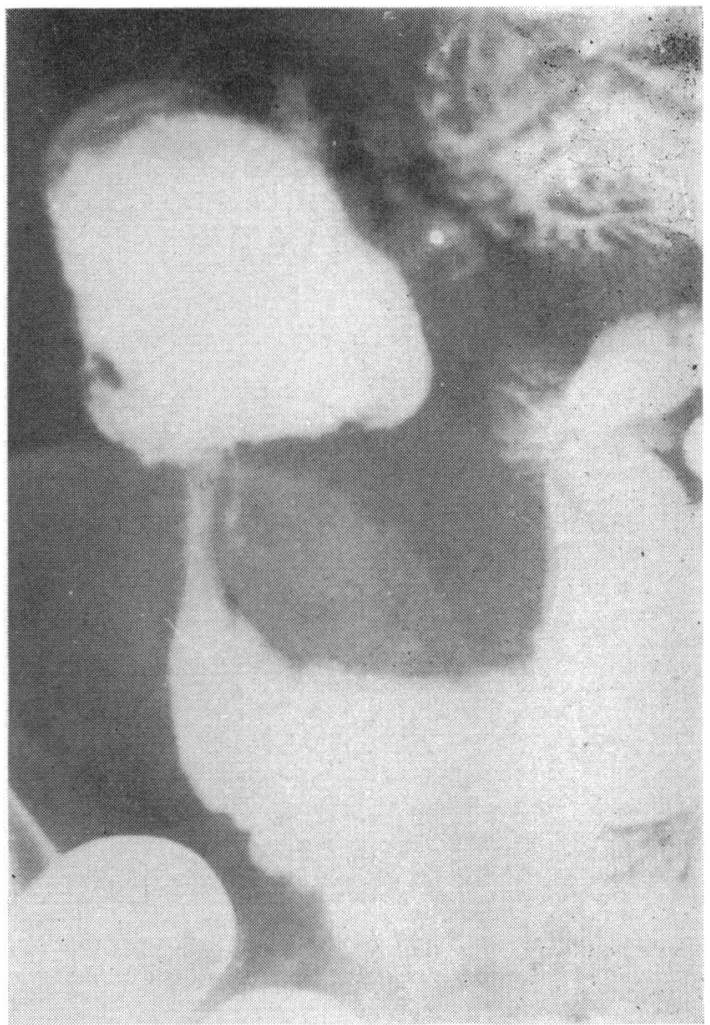

FIG. $4 b$

FIG. 4a. Case 3: Snall bowel enema showing filling of terimal ileum with rigid, narrowed segment. Crohn's disease. Note also adhesion of a proximal coil giving the typical acute kink and mucosal pattern.

FIG. 4b. Case 3: A later stage of injection than in Fig. $4 a$ showing filling of the colon and extraluminal track. Note adhesion again defined.

FIG. 5. Case 4: Small bowel enema showing typical deformity of carcinoma of colon. 


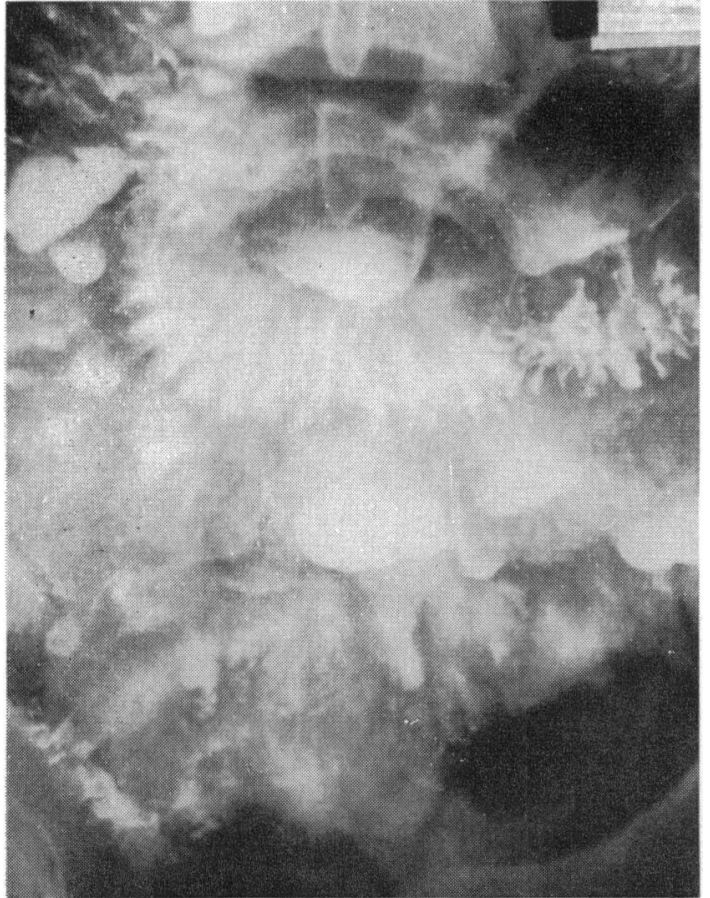

FIG. 6a. Case 5: Sniall bowel enema showing multiple jejunal diverticula. Note double contrast filling in the upper group.

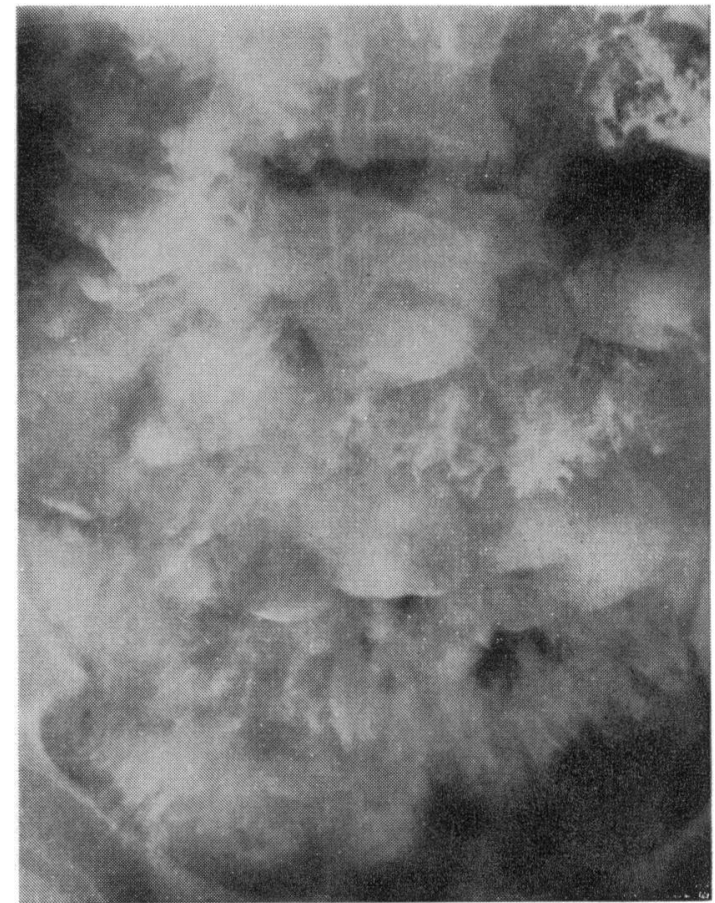

FIG. 6b. Case 5: Small bowel enema showing multiple diverticula in the lower jejunum and ileum. Note thin barium opacity allowing definition in spite of overlap.

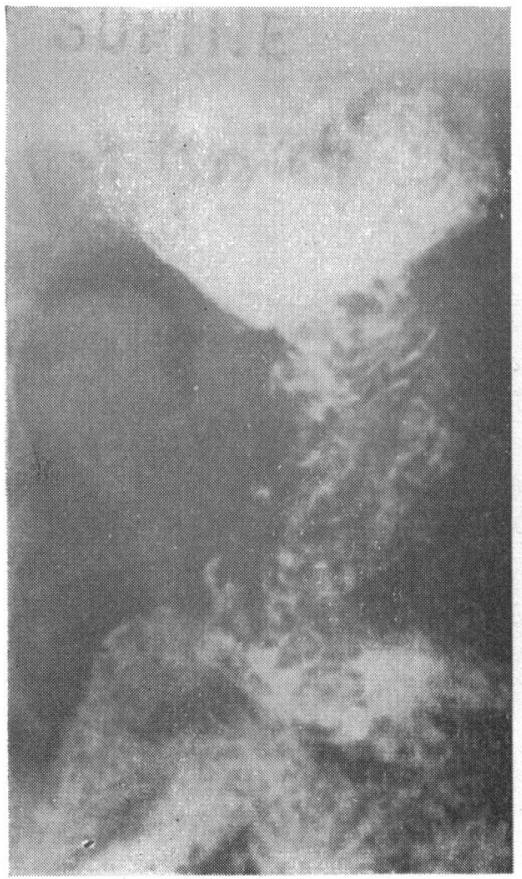

FIG. 7a

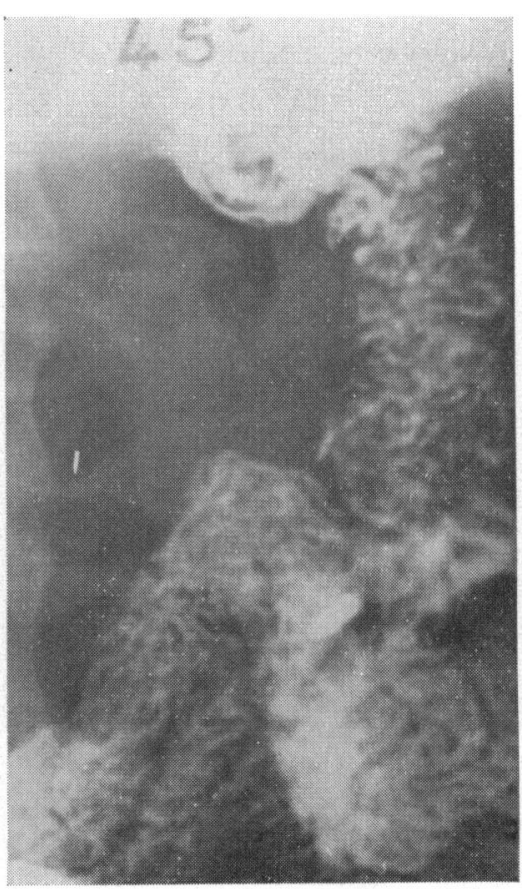

FIG. $7 \mathrm{~b}$

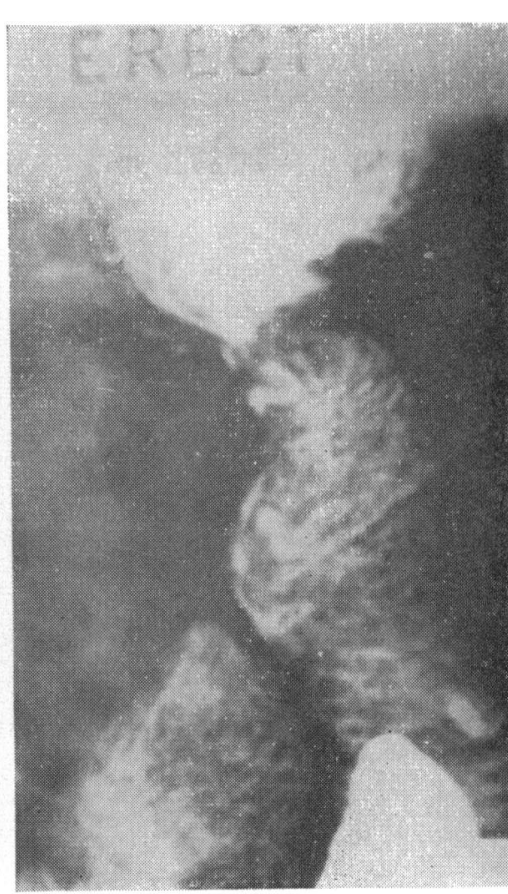

FIG. $7 \mathrm{c}$

7a. Small bowel enema demonstrating jejunal adhesion and showing loop of jejunum with smooth curve when the patient was supine.

7b. Slight tenting of loop with $45^{\circ}$ table tilt.

7c. Acute kink of loop with patient erect. 


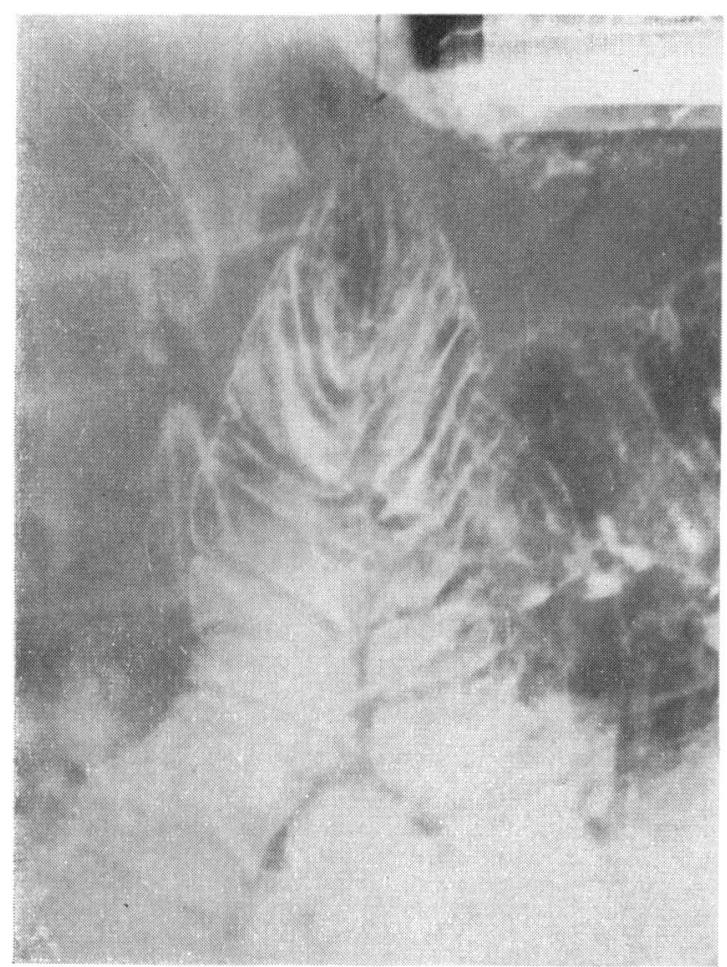

FIG. 8. Case 7: Small bowel enema showing jejunal adhesion as acute kink of loop and mucosal contrast pattern typical of adhesions tenting in the erect posture.

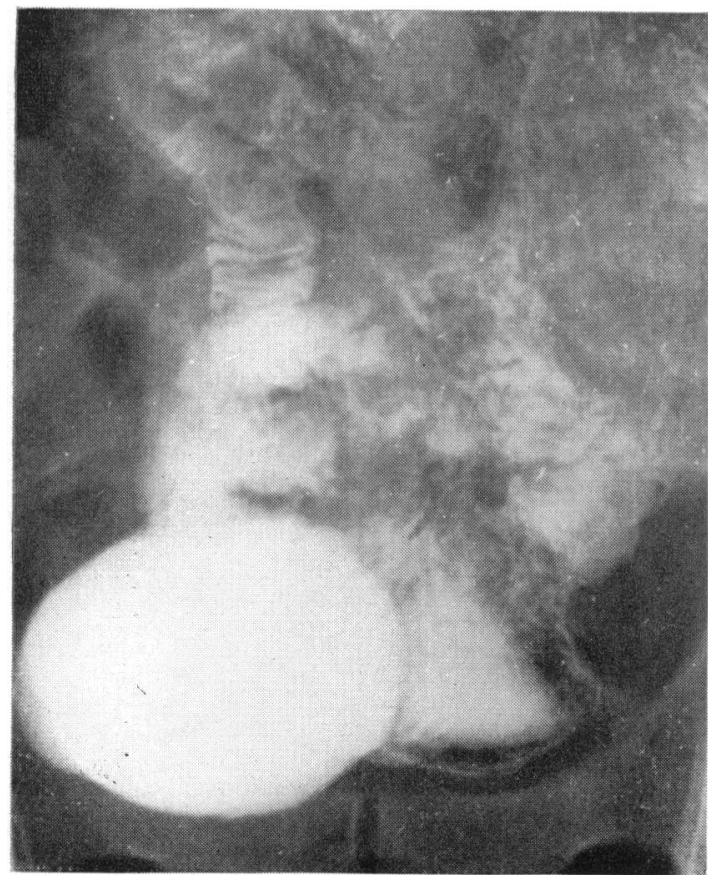

intestine in numbers quite unsuspected in the followthrough series (Figs. 6a and 6b).

CASE 6 W.M., a man aged 42 years, was referred by Dr. J. Simpson in February 1961 giving a history of gastrectomy for chronic duodenal ulceration eight years previously. Ever since a stormy post-operative recovery he has complained of vomiting bile and of a consciousness of abdominal distension after meals. A small bowel enema demonstrated an adhesion of the jejunum which was not recognized in the supine posture but became increasingly obvious as the table tilt moved to the vertical (Figs. 7a, 7b, and 7c). Operation by Mr. A. M. Loughran confirmed this adhesion which was separated.

CASE 7 T.K., a man aged 57 years, was referred by Mr. G. H. D. McNaught who had undertaken an emergency gastrectomy in February 1960. Immediate post-operative recovery was uneventful. The patient remained well until June when he developed abdominal pain reaching a climax in four hours necessitating admission to hospital as an emergency. A Gastrografin meal on admission showed no gastrojejunal ulceration. The acute phase settled with conservative treatment and the patient was referred for a small bowel enema which revealed a single acute kink in a loop of jejunum, accentuated in the erect posture, consistent with an adhesion causing sling fixation (Fig. 8). Operation by Mr. McNaught confirmed the presence of an adhesion which was a thick fleshy band attaching the loop of jejunum to the undersurface of the liver.

CASE 8 J.A., a man aged 38, was referred by Mr. J. E. Monro and admitted to hospital with a picture of

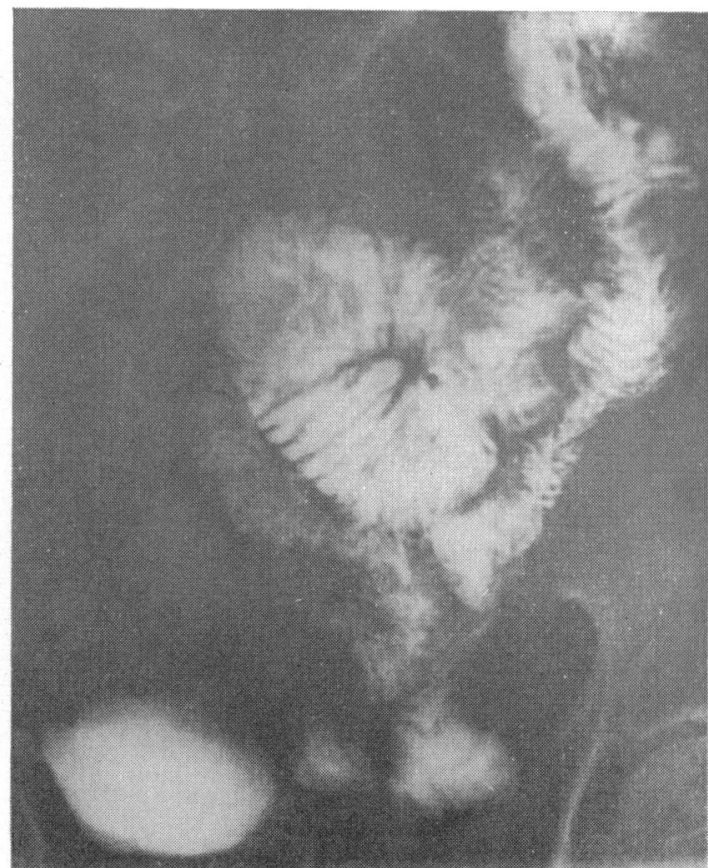

FIGS. 9a and 9b. Case 8: Small bowel enema showing two stages of filling to reveal partial ileal obstruction. 
subacute obstruction and a history of a gunshot wound of the abdomen in 1944. The obstructive symptons were relieved by conservative treatment and the patient was referred for a small bowel enema which showed partial obstruction in the ileum where the coils were matted together. The total length of the small intestine appeared abnormal suggesting that there had been a considerable resection and this was later confirmed from Army records. Operation was considered undesirable, if it could be avoided, and the patient has been kept under careful review and serious symptoms have not recurred to date (Figs. 9a and 9b).

\section{CONCLUSION}

We consider that the follow-through series can only be accepted should a definite positive finding result. A negative follow-through series should not be allowed to lead to a sense of security, so often proved to be false. We recommend the small bowel enema in any case in which the clinician suspects pathology of the intestinal tract and in which the barium meal and colon enema proved negative. It is not, in fact, and should not be, considered any more specialized a procedure than the double-contrast colon enema and we have not found it more time consuming. Certainly it cannot be excluded from the diagnostic armament in any case of obscure occult bleeding. Experience has shown that advantage lies in using a minimum of barium in order to prevent any possibility of overshadowing a small diseased segment. Finally, we would stress the necessity to examine with varying degrees of table tilt to ensure that an acute kink, due to an adhesion, is demonstrated. It is also of interest that the removal of the pylorus by gastrectomy does not allow satisfactory investigation of the small bowel by the ingested meal and intubation of the efferent loop is still necessary.

We wish to express our thanks to our clinical colleagues mentioned in the text and to Drs. Studdert and Rolland and Mr. Jamieson who also referred cases in their clinical charge for investigation. This method of examination could not have been carried forward without their encouragement. We would also thank Haley's of Carlisle for the great care taken in the preparation of the reproductions. Finally, we would record our appreciation to the radiographic staff of the Cumberland Infirmary for their help throughout this investigation.

\section{REFERENCES}

Badenoch, J. (1960). Steatorrhoea in the adult. Brit. med. J., 2, 963-974.

Greenspon, E. A., and Lentino, W. (1960). Retrograde enterography. A new method of roentgenologic study of the small bowel. Amer. J. Roentgenol., 83, 909-918.

Pygott, F., Street, D. F., Shellshear, M. F., and Rhodes, C. J. (1960). Radiological investigation of the small intestine by small bowel enema technique. Gut, 1, 366-370.

Schatzki, R. (1943). Amer. J. Roentgenol., 50, 743.

Scott-Harden, W. G. (1960). In Modern Trends in Diagnostic Radiology (Third Series). Ed. J. W. McLaren, p. 84. Butterworth, London. 